\title{
2 \\ GETTING LEANER, SMARTER AND MORE EFFECTIVE: OPPORTUNITIES AND CONSTRAINTS FOR GOVERNMENTS UNDER AUSTERITY
}

\author{
Doug McTaggart \\ Queensland Commission of Audit \\ and Queensland Public Service
}

I would like to approach this topic both from my perspective as a Commissioner of the Queensland Commission of Audit, and from my perspective as Chair of the Queensland Public Service Commission, sitting on the Public Sector Renewal Board. In these roles, I have been involved with my colleagues in trying to drive reform and renewal in this sector. Unfortunately 'trying' is the right word-because it is not easy, and because we are asking people to do some very different things.

\section{The economy and fiscal austerity in Queensland}

Where do we start? We know that governments around the world and in all Australian jurisdictions face two major problems, and I think these two problems get conflated. The first is how to balance the budget in the short term, over the next one to four years. The second and much more important problem is how to keep the budget balanced in the longer term without drastically reducing the quantum or quality of the services delivered. 
The first problem arose with the global fiscal profligacy fostered by an extended period of strong economic growth, abruptly ending when the resulting financial bubble burst and brought about the Global Financial Crisis (GFC) in 2008-09. Pre-GFC strong economic growth delivered strong revenue growth and with the fiscal shackles removed government spending increased, the large part of it being discretionary.

In Queensland in the decade to 2005-06, revenues were growing at 10 per cent per annum on average, and expenses at 7 per cent-a happy place for a government to be. In 2005-06 to 2010-11, this was reversed-revenues grew at 7 per cent per annum and expenses at 10 per cent, resulting in unsustainable deficits. And, of course, the ability of governments to fund deficits has met its limits - there are limits to a government's ability to tax, particularly in the states, and the size of the accumulated deficits to be funded by borrowing pushes past the tolerance of the markets. This has led to credit downgrades and subsequent increases in funding costs.

Now you might ask whether it matters that governments borrow and/or run deficits and that credit ratings get downgraded. As the Commissioner of Audit noted in Queensland's case, the interest bill paid on accumulated general government debt rose from $\$ 173$ million in 2005-06 to $\$ 1.9$ billion seven years later in 2012-13 (Australian Bureau of Statistics (ABS) 2013, Table 1). This is a rate of increase of over 40 per cent per year and the bill is rising to approximately \$2.5 billion in 2015-16 (Queensland Commission of Audit 2012, Chart 1.6). This is by far the fastest-growing component of general government expenses, all of which must be paid from general revenue.

The opportunity cost (an economic concept, but a very important one) of this debt payment to foregone government services is very large but is often not questioned. As to the credit downgrade Queensland incurred in 2009, the accumulated cost of the margin spread - that is, the difference between an AAA and an AA rated borrower-has pushed past $\$ 330$ million to date and is increasing by about $\$ 150$ million per annum (Queensland Commission of Audit 2012, Chart 2.9; see also Queensland Treasury updates). This is occurring in a low interest rate environment that will not last, and while the Queensland government remains on negative credit watch. Simply adding these up shows that the cost of the credit downgrade alone will soon be more than half a billion dollars. Again, what services could half a billion dollars fund?

In its June 2012 interim report, the Commission of Audit (2012) recommended the Queensland government act quickly to stabilise the growth in debt and deliver a fiscal surplus that met all operating expenses and all current and planned general government capital expenditure in the budget timeframe. In an accrual sense, this means an operating surplus sufficient to cover all operating 
capital expenditure. Consequently, of course, a period of fiscal repair - what we call 'austerity' here in Queensland - was implemented, culminating in the loss of 14,000 public sector positions in a short period of time. Looking at the recent budget projections, the result of this fiscal repair is that the government has accomplished an astonishing feat in bringing about a turnaround; expenses that were growing at 10 per cent per annum now show almost no growth within the current and forward estimates period. The expected rate of increase in expenses in this most recent budget was the lowest since 1998. This brought about an abrupt and painful episode of fiscal austerity. It was to some degree indiscriminate, a blunt instrument - but it had to be done. The growth in debt will be stabilised at a significantly lower figure than previously anticipated.

But let us not confuse fiscal repair or forced austerity with reform. It was costcutting, and in some cases cost-cutting can be inimical to productivity growth. Still, it has set the platform and focused minds on the large-scale reform of public service delivery that must lead to significant productivity increases.

This brings us to the second and more important problem. As the Commission of Audit described, and as governments around the world are discovering, the next decade almost certainly will not yield the revenue growth of the pre-GFC decade. In Queensland's case, lower economic growth caused by declining interstate migration, an ageing population increasing demand for some services and slowing growth in Commonwealth tax receipts (which of course flow through all the states) are factors that put increasing pressure on the budget. The audit report produced a chart showing that on a 'no policy change' basis, or on a 'business as usual' basis, the expenditure gap manifesting a budget deficit would be 3 to 4 per cent of gross state product (GSP) by 2025, rising to around 15 per cent of GSP by 2050 (Queensland Commission of Audit 2013, Volume 1, Chart 2). Of course, we will not get to that position because neither markets nor the electorate will allow it: credit downgrades and election losses would precipitate action through crisis management and fiscal repair, or forced austerity would come into play long before such apocalyptic scenarios emerged. Then Queensland would very quickly find itself in the same position as last year, looking at equally draconian measures.

But this is precisely the point. Governments today have the opportunity, as they have always had, to cut calmly and with forethought - to plan now for a measured and reconsidered reform of the way services are being delivered. The key message from the Audit Commission report is that 'business as usual' is not an option. The report shows that productivity improvements in government service delivery of $0.8-1.1$ per cent per year will be required to maintain a stable fiscal position, given the current and expected level of demand for public 
services. This is equivalent to reducing the unit cost of service delivery in 2050-51 by one third of what it would be on a 'business as usual' basis - that is a big ask.

\section{Improving public sector productivity}

This is not just an issue for Queensland. Work produced by Accenture (2012) in conjunction with Oxford Economics shows that by 2025, the expenditure gap across a range of countries will be between 1.5-5 per cent of gross domestic product (GDP), averaging around 3 per cent. In other words, the fiscal position of many countries on a 'business as usual' basis is not sustainable. Accenture notes that the average annual productivity or public sector efficiency increase required to bring about fiscal sustainability is about 1 per cent each year. So there is widespread agreement that ongoing efficiency and productivity improvement is necessary in the delivery of public services, and this is the challenge.

Yet even here there are voices of dissent. One prominent critic dismissed the recommendations for sustained productivity improvement as wishful thinking, claiming that it's been tried before on many occasions and failed each time (Quiggin 2013). Moreover, there was a good theoretical reason as to why, enunciated by William Baumol in the 1960s and now known as the 'cost disease' (see e.g. Baumol and Bowen 1966). As an example, it is difficult to get productivity improvements out of a symphony orchestra - the orchestra can only play so fast. Looked at another way, an orchestra might have four trombones. It is not really feasible to dispose of trombones 2, 3 and 4, and say, 'We are going to work trombone 1 harder and smarter'.

And so goes the argument-many if not most public services are similarly delivered, therefore it is impossible to get productivity improvements in the public sector, ergo the Commission of Audit was a waste of time. Even worseand here is where the 'cost disease' comes in - if wages are driven at the margin by productivity growth in other, more flexible industries then not only will productivity not rise in the public sector but wages will rise - the result of an economy-wide labour market. So costs of public service delivery, and of our philharmonic orchestra, will also inexorably rise without concomitant productivity increase.

It all sounds too easy to simply accept the status quo with no other options but to increase taxes or cut services. This is simply wrong because at a minimum there are benchmarks available that indicate that productivity can improve. The Commission of Audit report is replete with examples of where the private sector is demonstrably more efficient than the public sector at delivering the 
same services. Gary Sturgess, in a speech to the Victorian Institute of Public Administration, suggests that from what benchmarking and market testing data we do have, the average increase in productivity available to the sector is in the order of 20 per cent. He goes on to say that 'a quarter of the national economythat is the public sector - is capable of making productivity gains of that order over the short to medium term should be a national scandal. It isn't' (Sturgess $2013,1)$. We know a significant proportion of public service delivery is already provided by the non-government sector, but even here, with better and more contestable outsourcing arrangements, we can improve efficiency.

If the above is debatable, the following fact is not: some jurisdictions are better at some activities, or are more productive on average. This suggests that simply learning from each other, picking the best means of production, will yield benefits. On Commonwealth Grants Commission data, Queensland is 5 per cent more costly in terms of service delivery than the national average, and 10 per cent more costly on average than New South Wales (Queensland Commission of Audit 2013, Volume 1, Chart 5). Using Australian hospital statistics from the Australian Institute of Health and Welfare (AIHW 2012), in 2010 Queensland was 8.2 per cent more costly than the national average when it came to cost per case with adjusted separations, and nearly 20 per cent more costly than Victoria (Queensland Commission of Audit 2013, Volume 1, Chart 7). So without much thought about new delivery methods, simply adopting existing best practice should yield significant gains.

So, let me come back to 'cost disease' and test the underlying assumptions. I think we recognise that the basic structure of a philharmonic orchestra is a given. These are what an economist would call fixed coefficient processesthe capital to labour ratio cannot change without a significantly diminished quality of output. To produce more output requires proportionately more of every input. Is this true for most public services? I don't think so. Is the doctor to nurse to equipment to administrator ratio for each patient in each medical service fixed? Is a given class size the only determinant of education quality? Do sworn police officers have to operate speed cameras? Is there only one way to deliver the myriad of other services as mandated by the public sector? Again, I don't think so. This means there are different, perhaps more flexible, production processes to get the necessary outputs into the hands of the public who demand them.

Asking what the taxpayer actually wants is probably a good start; allowing the purchaser some say in what they get will probably help. Catering for increased demand by simply expanding current activities using current processes (as if the production processes were fixed) will drive us to an unsustainable fiscal outcome more quickly. This is what the Commission of Audit meant by its key theme: 'business as usual' is not an option. 
By all means, every jurisdiction should avail itself of best practice from other jurisdictions or the private sector. This will bring about a one-time reduction in costs or increase in productivity. There is no excuse for not doing this. But this will not deliver a sustained increase in productivity growth, and given all jurisdictions are in the same long-run boat toward fiscal unsustainability, new and different methods of service provision are required.

Perhaps the difference here is the following (and here I will slip into public sector language): it is commonplace in the sector to think of inputs through a production process as delivering measurable outputs. Outputs, we believe, have a predictable effect on achieving desired outcomes, but outcomes themselves are often hard to quantify. By adopting best known production processes from other jurisdictions or the private sector, we get an increase in outputs per use of given inputs. This is a one-time rise in productivity. We can then think about changing and improving the production processes to get the same outputs for fewer inputs, producing an improvement in productivity. This, I think, is what Sturgess (2013) refers to as the 'how' of improving productivity. If this latter activity can be sustained we have ongoing productivity growth, but I suspect there are limits to how far any given production process can be pushed.

Now we come to the 'what'. More radically, we can think about how to use our inputs to get better outcomes by delivering different outputs. This is harder, but it is true reform. For example, we might improve the operation of juvenile detention centres, perhaps by outsourcing to the private sector to reduce costs and thus getting better productivity. Or we might incentivise an operator (public or private) to, while securely detaining juveniles, undertake appropriate interventions or case management so that individuals are less likely to reoffend, with repayment related to the rate of recidivism. How they do this may not be rigorously prescribed, leaving the design and the operation of the centre with the operator - but payment could be by outcome, which in this example would be the reduced rate of recidivism. In a case such as this, we would need to think about whether or not a public operator could deliver the same response as a private operator. I think it would be harder for a public operator.

\section{'Business as usual' versus public sector reform}

This brings me to the big question: can the public sector, on its own account, radically reform? I think this is also very hard. We know that governments and the public sector exist to deliver outcomes when the market itself breaks down. Because market failure arises from a variety of possible sources, the public sector of necessity fills the gap. But this creates the sector as a monopoly provider with no competitive discipline from the market. The monopoly provider is 
not under constant external pressure to reduce costs and so to innovate, and it becomes very difficult for the sector to discipline itself on an ongoing basis. As others have noted, it often takes a crisis or a threat of crisis to precipitate action. However, threats and their crises eventually dissipate and the sector is very good at outlasting crises. 'Business as usual' generally prevails.

This is what led the Commission of Audit to recommend much greater use of the non-government sector in actually delivering services. The Commission recommended that the public sector become a facilitator rather than a doer wherever possible. If the public sector were accountable for ensuring that other non-government providers deliver promised outcomes, it would be less likely to be captured by its own investment in a particular way of delivering services. Of course, government providers will always have a key role in providing services that have large 'public good' components, where markets generally fail. But the range of services that fall into that category is surely much more restricted today than it was in even the recent past. Advances in contracting practices, effective regulation, and risk management, mean that non-government providers can, with confidence, be tasked to do more. This is especially true if the public sector can direct its creative skills toward clever market design, thus ensuring that outsourced activities continue to be subject to cost competition and innovation (both to reduce costs and to yield better outcomes).

The key here is that the public sector, which has always had an administrative approach, finds it hard to be at the same time commercial. What usually happens is that commercial practices themselves become administrative and so fail to be commercial. Even if the public sector periodically shakes itself up there is no ongoing competitive or other pressure to continue to shake the sector. I think there should be a conscious decision by the public sector to willingly step back and commission others to do the work. The sector can then focus on designing policy and administering the contractual basis of non-government provision in accordance with that policy. The contracted providers can be constantly subject to competitive pressures related to quality, cost and the effectiveness of outcomes delivered. Competition will drive productivity growth through innovation.

\section{Improving ourselves out of a job}

There are 60 recommendations in the Commission of Audit report, designed to push the boundaries of public sector service delivery thinking. These cover the entire gamut of government service delivery, including health and hospitals, aged care, education, vocational training, disability services, police services and corrective services. There are instances where more rather than less government 
involvement may be required. For example, suppose all bus services in a given area were put out to tender for private provision. It might make sense for the government to step in and buy all the depots so that none can be used as a source of monopoly power. Alternatively, if a current government service competes in the market with two private duopolists, it might make sense for the government to encourage or facilitate a third private player into the market to promote greater competition. Both these examples are what I would class as creative market design - an area where the public service needs greater expertise.

The Commission of Audit implementation in Queensland has now been combined with a public sector renewal process where agencies are being asked to fundamentally re-evaluate their reason for existence. They are being asked to consider the following: Who are our customers? What services have they been promised? What is the best way of delivering on that promise? Beginning with and embracing the customer is important. Embracing contestability of service provision will drive much of this thinking.

Here, perhaps I disagree with those who maintain that we will always have large government. Is it too far-fetched to imagine a sector that has become so creative it actually works itself out of a job? Or something close to that, where a much reduced public service facilitates the non-government sector in bearing the delivery load while maintaining and improving quality and value for money? To me, that would be a measure of success. As a chief executive officer (CEO), I've always believed that a good CEO works himself or herself out of a job by building processes and a senior management that can make the CEO redundant.

Perhaps that is how the public sector should think about itself. Engaging in further program cutting, zero-based budgeting or other measures to reduce inputs and therefore reduce costs might not be the best way to go, particularly if we do not have a clear idea of what is the best way of delivering services to the public. Agencies need to address the question of why they exist and what they should do before they decide on how to do it.

\section{Difficulties in the reform of public sector delivery}

Let me address the difficulties and obstacles to reform I have noted over the past 12 to 18 months.

First, the capacity and capability constraints within the sector: moving from doing to facilitating and overseeing requires different skill sets and capabilities, which have been poorly developed in the past. Queensland has committed to buy, borrow and build the requisite skills in procurement, contract negotiation, contract management and innovative market design to progress its agenda. 
It has also become apparent that the capability of the non-government sectors needs improvement. Although willing, NGOs and the private sector are still building capability and capacity and cannot currently handle the full extent of government outsourcing that could emerge. Growing capability will be a joint endeavour.

Second, and equally importantly in the public sector, is creating the capacity to think about planned implementation of change. In an austerity environment it is easy for an agency to say, 'We simply don't have the resources'. But is it really credible, in a sector with around 220,000 people (as in Queensland), where performance management has not been exercised for decades, that people or funds cannot be found or released from other duties to undertake the task? If we do not create the capacity to seriously think about reform then it will be relegated and squeezed into 'business as usual' activities, as I think we are seeing in Queensland. 'Business as usual reform' is an oxymoron.

Third, we are discovering that we really do not know how to specify many of the outcomes, and the outputs that deliver these outcomes, with sufficient clarity for the purposes of contracting. This is not an excuse for not introducing contestability and outsourcing, nor is it a reason to not engage in recommissioning services that are already outsourced. But it is an indication of just how poorly defined many current in-house activities are if they cannot be quantified. If they cannot be quantified, how can we ever measure productivity or value for money? Here, I think, is an area where the Australia and New Zealand School of Government (ANZSOG) can significantly contribute by helping to define and build the tools that enable us to measure the compendium of services currently provided to the public.

Fourth, reform must come from the centre. It is a whole-of-government activity. Trying to think about and implement reform within any given agency setup would limit the extent of reform because so much actual service delivery cuts across well-defended agency boundaries. The Queensland government recently set up a social services subdivision of cabinet as one way of dealing with this issue, requiring the respective directors-general to similarly interact. There needs to be more of this. In Queensland, every agency - from police to emergency services, health and disabilities, and housing-operates under a different regional breakdown of the state. Each goes about piloting new activities in different regions. With a consistent regional structure and a consistent implementation of pilot studies we would get a much better picture of the overall outcomes because we would internalise the mutual dependencies that are currently largely ignored. At the centre, we ourselves are still learning how to promote, encourage and direct the task of approaching reform. 
Fifth, we need a new approach to risk-taking. If 'business as usual' is not an option then innovation must prevail. However, innovation requires taking risks, which is not something that sits easily within the current culture of the sector. The perceived approach of auditors-general also needs to change. I am advocating for the development of a risk framework that encourages sensible risk-taking, and it would be helpful for auditors-general to provide guidelines on sensible, managed risk-taking that allows, under very measured circumstances, for the prospect that innovation might not work.

More generally and more importantly, we must actively prepare the hearts and minds of the sector to embrace a culture of reform. If all public sector employees do not accept the need for reform they will not actively participate and may well passively resist. While it is vital to have CEOs and senior management on board - which I think is largely the case in Queensland - we also need the people at the coalface. This requires a massive change in culture and values, and we know this does not happen spontaneously.

As an example, we have produced a manual for introducing contestability into the Queensland public sector. It is 40 pages long and I was aghast when I heard this. Having read it and recognised the low base we come in on, I now believe that in the hands of a passionate advocate for reform this is a powerful and comprehensive tool. However, in the hands of someone not committed to reform it is 40 pages of reasons why contestability cannot and will not work.

Culture change must be driven within a believable context, an all-encompassing narrative. In the public sector - an industry with one of the highest labour-tocapital ratios of all industries, and which professes constantly that people are its most important asset - the complete absence of a strategic human resources capability across the sector and in most agencies astonishes me. How will we effect the necessary change to bring about sustained productivity increases and enhance value for money outcomes if we cannot equip our people to do so? I see little evidence that we have made much progress in this direction, and it must occur now. If it doesn't, all the measures we peddle about reform, all the processes we push out to encourage reform, will be seen as just that - new processes to be put alongside all the others we have dreamed up over the years.

To conclude, there is a dire need to generate sustainable productivity growth in the delivery of public services. This cannot come from doing things the way we have always done them. Short-term gains should be accessed by adopting best practice from other jurisdictions and the private sector, but sustainable productivity growth can only come from doing things differently. This requires a fundamental introspective analysis of why the sector exists, at an agency and 
a whole-of-government level, as well as a search for the best way to deliver the defined services. Moving from a doing role to a facilitative role will be a good start.

This will not be easy and many challenges need to be addressed along the way. The public sector needs to be prepared to embrace and chase change to deliver productivity growth, and I think ANZSOG has a very important role in helping lead that chase.

\section{References}

Accenture. 2012. Delivering Public Service for the Future: Navigating the Shifts. Online: www.accenture.com/SiteCollectionDocuments/PDF/AccentureDelivering-Public-Service-for-the-Future-112812.pdf (accessed 9 July 2014).

Australian Bureau of Statistics (ABS). 2013. Government Finance Statistics, 201213. Cat. 5512.0. Canberra: ABS.

Australian Institute of Health and Welfare (AIHW). 2012. Australian Hospital Statistics: 2010-11. Health Services Series No. 43. Canberra: AIHW. Online: www.aihw.gov.au/WorkArea/DownloadAsset.aspx?id=10737421722 (accessed 9 July 2014).

Baumol, William J. and William G. Bowen. 1966. Performing Arts, the Economic Dilemma: A Study of Problems Common to Theater, Opera, Music, and Dance. New York: Twentieth Century Fund.

Queensland Commission of Audit. 2012. Interim Report - June 2012. Online: commissionofaudit.qld.gov.au/reports/interim-report.php (accessed 14 January 2013).

Queensland Commission of Audit. 2013. Final Report - February 2013. Brisbane: Queensland Government. Online: commissionofaudit.qld.gov.au/reports/ final-report.php (accessed 14 January 2013).

Quiggin, John. 2013. The Queensland Commission of Audit Final Report: A Critical Review. RSMG Working Paper Series. St Lucia: University of Queensland. Online: www.uq.edu.au/rsmg/WP/Australian_Public_Policy/ WPP13_1.pdf (accessed 2 July 2015).

Sturgess, Gary L. 2013. 'If your only tool is a hammer ....' Speech to the Victorian Institute of Public Administration, Melbourne, Victoria, 25 June. 
This text is taken from Managing Under Austerity, Delivering Under Pressure, edited by John Wanna, Hsu-Ann Lee and Sophie Yates, published 2015 by ANU Press, The Australian National University, Canberra, Australia. 